\title{
A Teaching-Free Robot System Utilizing Three-Dimensional CAD Product Data
}

\author{
Yoichi Nagao, Hideaki Ohta, Fumihiro Honda \\ Kawasaki Heavy Industries, Ltd. \\ Japan
}

\section{Introduction}

The recent shortage of experienced workers and the trend toward better working environments have accelerated the introduction of robots into manufacturing sites. This in turn has highlighted the need for more efficient teaching methods of robots. Conventionally, industrial robots are taught online. With this method, the production line had to be halted at every teaching sequence, which adversely affects production efficiency. More recently, offline teaching has become common using computer-based robot models (Kobayashi et al., 2001). While off-line teaching does not stop the operation of the production line, teaching demand is intensive for the production lines where many different products are manufactured in small lots, leading to high operator workload and pushing up production costs (Nagao \& Onoue, 2000).

The authors have been engaged in research into an automatic NC data generator named Kawasaki Common Off-line NC data Generator (KCONG) (Nagao et al., 2000a). KCONG generates action data for a robot based on the design information from a three-dimensional CAD unit without the need for any human intervention or teaching. Recently, the authors have developed some teaching-free robot systems by combining KCONG with welding, cutting, painting and other industrial robots (Nagao et al., 2000b).

This chapter introduces one such system, a teaching-free robot system for welding large box structures using KCONG, which was delivered to a client and is now operating successfully (Nagao et al., 2001).

\section{System Overview}

\subsection{Applicable operations}

The system is designed for large box structures more than 4 meters in length and to which grooves. Weld lines may be straight, curved or a combination. Boxing at the ends, connecting beads, applying multi-layer beads and continuous / intermittent welding are also possible. 


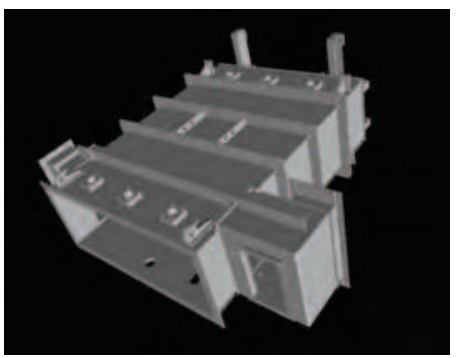

Fig. 1. A typical workpiece.

\subsection{System configuration}

The system consists of a three-dimensional CAD unit to design workpieces, the NC data generator KCONG, a line controller and a welding robot equipment. As shown in Fig. 2, the robot equipment consists of a three-axis moving unit - longitudinal, lateral and vertical and a six-axis robot suspended perpendicularly from the moving unit. Since weld joints are located on both external and internal surfaces of the box, each workpiece is positioned in different orientations during welding: sideways, sideways but reversed, and upright. The robot enters the box to weld the internal surfaces.

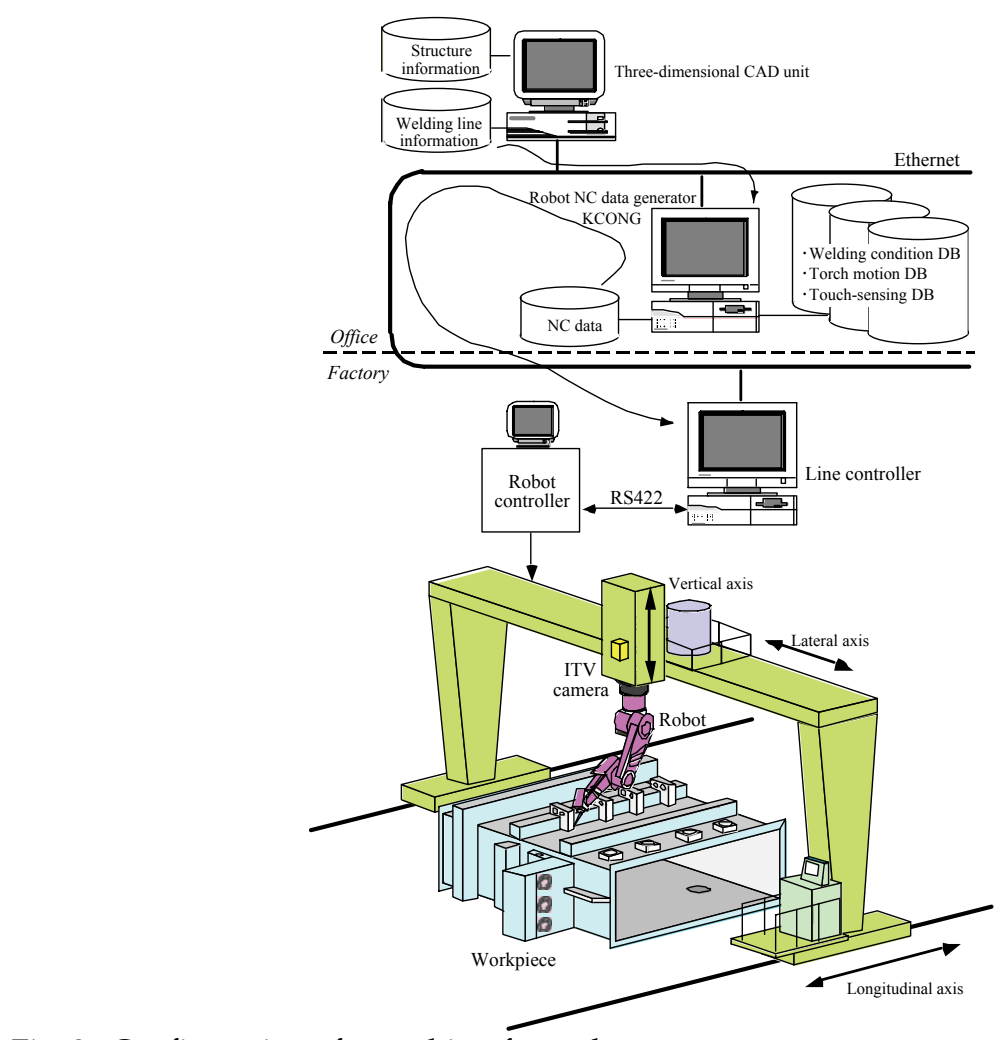

Fig. 2. Configuration of a teaching-free robot system. 
Data flow through the system is as follows:

(1) Three-dimensional configuration data and welding-related data for the workpiece are output from the three-dimensional CAD unit. Configuration data is output in a general-purpose CAD format (VRML). Welding-related data includes weld line positions, types of grooves, welding conditions, torch orientations and the positions of workpiece reference points.

(2) KCONG reads the configuration data and welding-related data from the CAD unit and generates NC data by referring to its databases. Calculations are all performed automatically to determine the robot orientation, check for interference between the robot and the workpiece, and plan the welding sequence.

(3) The NC data generated by KCONG is sent to the line controller via a LAN.

(4) The line controller measures the position of the workpiece using an ITV camera installed on the moving unit. The NC data is corrected based on the measurement results and the corrected data is then sent to the robot controller, which generates a weld execution command to the robot.

\section{NC Data Generator: KCONG}

The NC data generator KCONG generates NC data for the robot, as shown in Fig. 3.

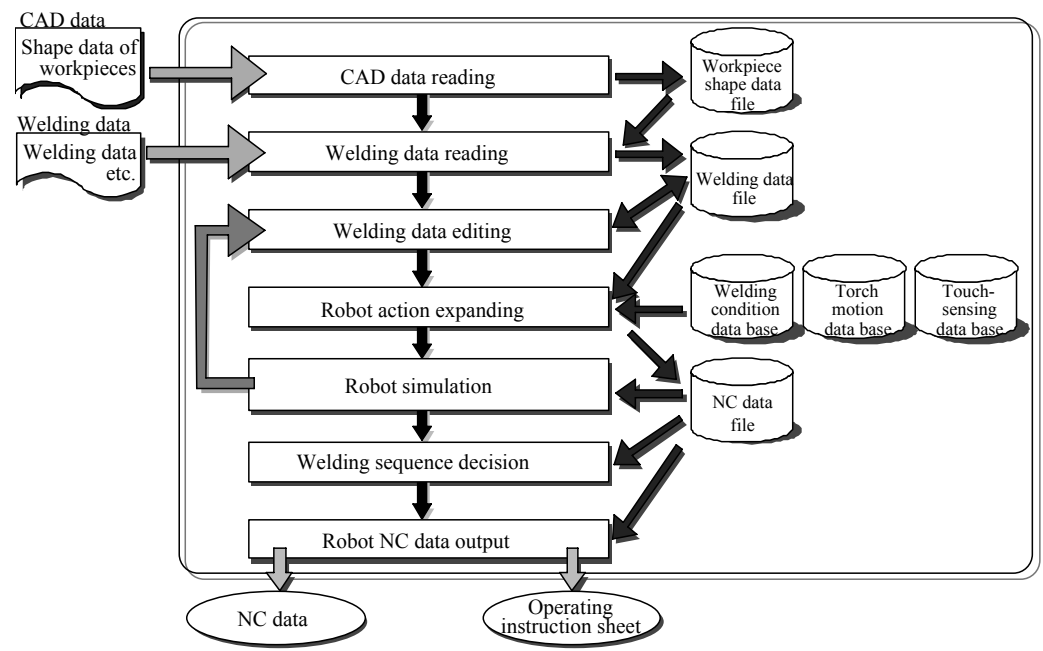

Fig. 3. The procedure for generating NC data with KCONG.

\subsection{Reading CAD data}

After reading the configuration and welding-related information for the workpiece from the three-dimensional CAD unit, the generator KCONG performs the following tasks:

(1) Shortening weld lines: If a weld line is detected to be out of the range in relation to the weld area due to the shapes of the parts to be welded, it is shortened.

(2) Dividing weld lines: If there is a point on a weld line where welding has to be stopped due to the presence of one or more crossing members, the weld line is divided into shorter lines as required. 
(3) Concatenating weld lines: To minimize the air cut time, weld lines are concatenated where possible.

When the above tasks are completed, the workpiece configuration and weld lines are displayed on the screen three-dimensionally. It is possible to zoom in and out of the image on the display, and change the viewpoint as needed.

\subsection{Generating NC data}

When creation of NC data is requested, KCONG generates it as follows:

(1) Determining the torch orientation: The torch orientation is determined for each weld line based on the conditions surrounding the line, and the position of the base (root) of the robot and its configuration are determined from the torch motion database.

(2) Determining welding areas: Simulation is carried out at small intervals along each weld line to check if there is interference between the robot and the workpiece. If there is interference, KCONG returns to step (1) to select a different torch orientation; this process is repeated until the interference is resolved. If interference persists, the torch orientation that minimizes the unwelded area is chosen. In Fig. 4, part B near weld line PQ and part $C$ that is attached to part A interfere with the welding torch, making welding impossible in two areas.

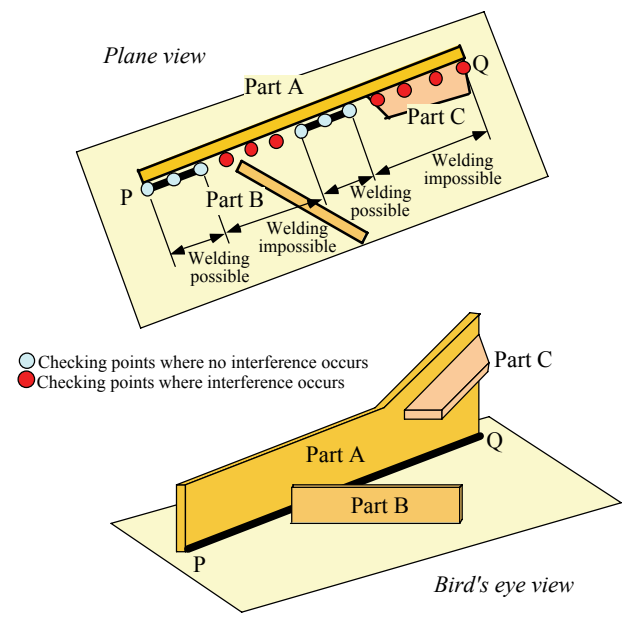

Fig. 4. Determination of welding performable area.

(3) Determining the touch-sensing path: Touch-sensing paths that would assure accurate detection of parts without interference are determined from the touchsensing path database (see Fig. 5) and the surrounding conditions at the ends of the weld lines. For example, in Fig. 6, there is a hole in the area where the welding wire should touch. KCONG acquires this information and modifies the sensing path, from solid lines (1) to (3) according to $(i, j)=(0,0)$, to broken lines (1) to (3) according to (i, $\mathrm{j})=(20,0)$ in the touch-sensing database.

(4) Determining approach / departure paths: KCONG determines the interference-free approach and departure paths for the chosen torch orientation by referring to its databases and by conducting simulations. 


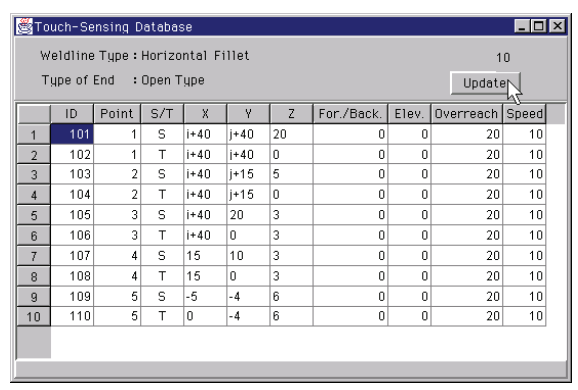

Fig. 5. An editing window of the touch-sensing database.

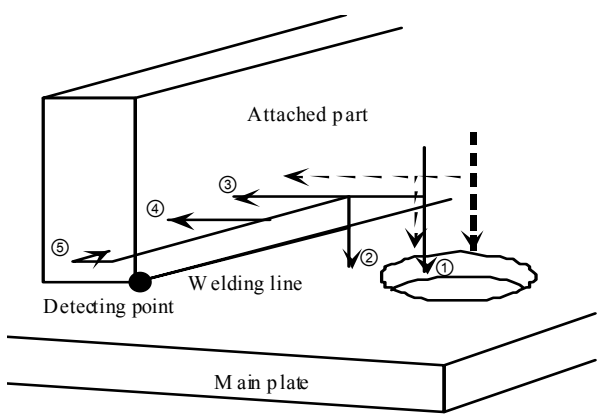

Fig. 6. Automatic selection of a touch-sensing path.

(5) Simulating entire welding procedure: After acquiring from the databases the welding conditions and torch motion at the ends of the weld lines, KCONG simulates the approach, touch-sensing, torch motion at the ends, regular welding, and departure in order to verify the NC data that has been just created. See Fig. 7 for an example simulation display.

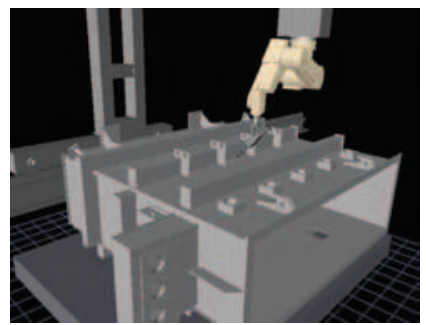

Fig. 7. A graphical display for the robot simulator.

At this point, the robot NC data has been generated. The operator can modify the data in the databases as necessary: welding conditions, touch-sensing paths, and torch motion at the ends of the weld lines. Even if automatic NC data generation is not possible, an operator can create a robot action program by directly teaching the computed robot model.

\subsection{Outputting NC data}

When NC data output is requested, KCONG outputs the NC data in the following manner: 


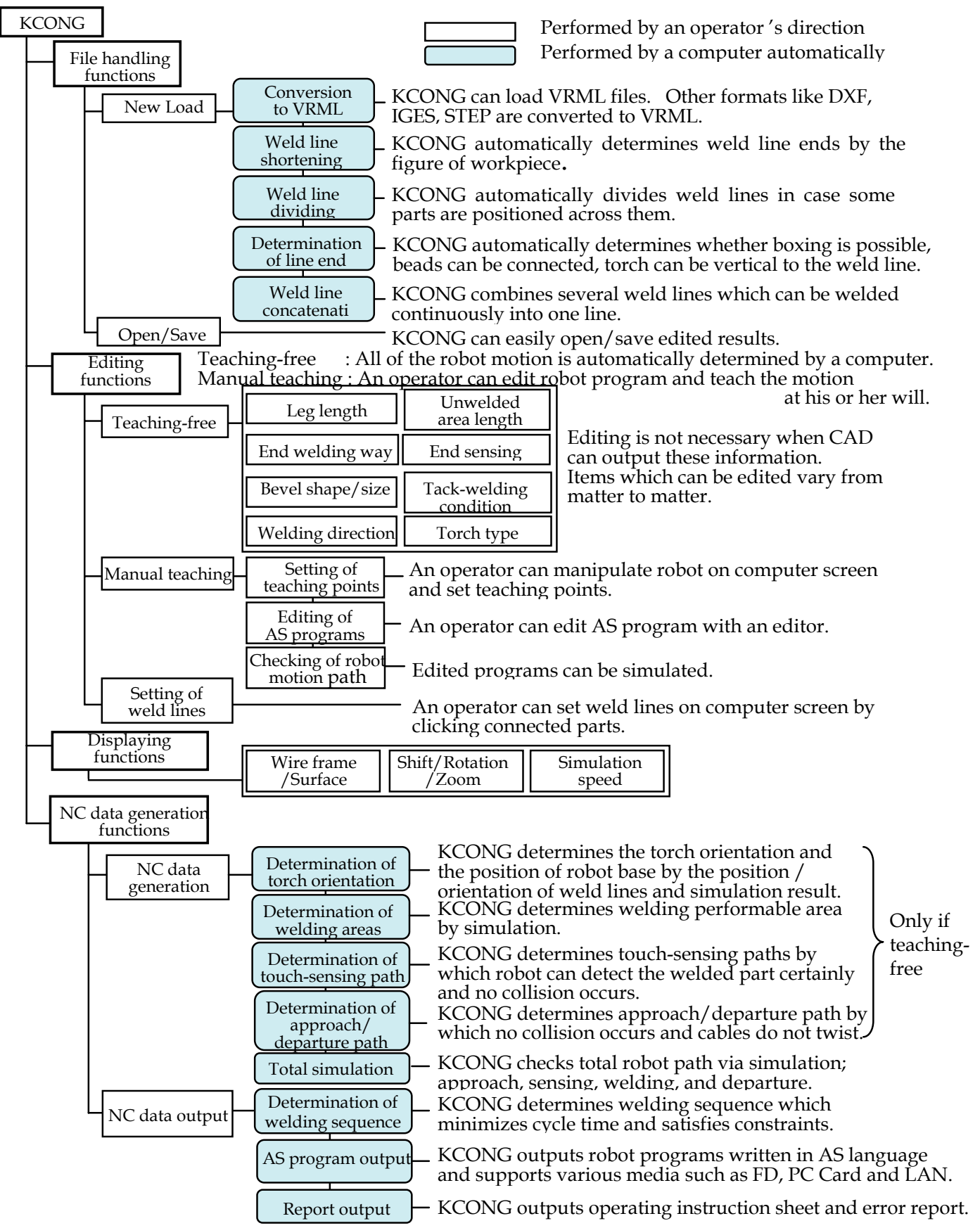

Fig. 8. Function tree of KCONG. 
(1) Determining the welding sequence: The welding sequence is determined so that all the preset conditions are fulfilled and the cycle time is minimized.

(2) Outputting the NC data file: The NC data is output as a file in the robot language format. The file is then transferred to the line controller via the LAN.

(3) Printing the operating instruction sheet and error report: Instructions for the operator, error reports and operating time estimates are printed.

The function tree of KCONG is shown in Fig. 8.

\section{Line Controller}

The line controller controls the entire system. It has the following five functions:

(1) Selecting the correct data for the workpiece: When a workpiece is fed onto the operation stage, the line controller selects and loads the appropriate data for that workpiece from the NC data created by KCONG.

(2) Teaching the reference points: This function teaches the robot to measure the three reference points on the workpiece set by the three-dimensional CAD unit. The process starts by aligning the crosshairs of the ITV camera installed on the moving unit with the reference points, thus measuring the workpiece placement in the longitudinal and lateral directions. The touch-sensing function then enables automatic measurement of the reference points in the vertical direction.

(3) Controlling sequence: This is the function that sequentially executes welding for each weld line on the workpiece. After correcting the NC data for the first weld line based on the measured reference point positions, the line controller sends the data to the robot controller with the welding start command. While the first weld line is being worked, the NC data for the next weld line is sent to the robot controller to eliminate any wait.

(4) Troubleshooting: If a problem arises while a weld line is being worked, the sequence for that weld line or for the entire workpiece is skipped.

(5) Monitoring: The line controller monitors the operation of the robot for any errors that might occur; the status of the robot is displayed in real-time on the screen as it operates.

\section{Welding Robot Equipment}

The robot used is the Kawasaki Arc Welding Robot JA-10. The gantry-type moving unit has three axes: longitudinal (stroke: 8.5 meters), lateral (4.3 meters) and vertical (2.4 meters). The six-axis welding robot is hung from the elevating section of the unit. Fig. 9 shows a general view of the welding robot equipment.

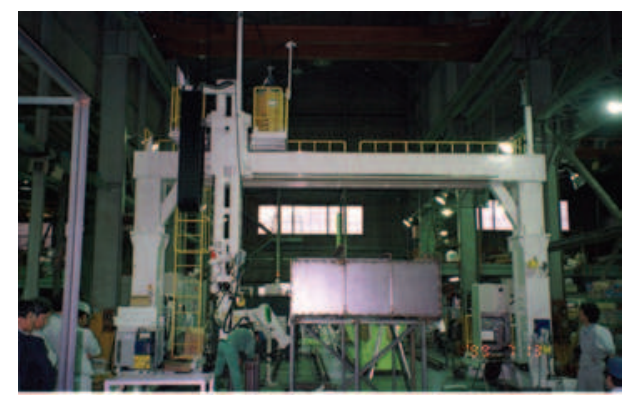

Fig. 9. General view of the welding robot equipment. 
To increase the rate of automated welding for complex workpieces, the robot has three types of welding torches: straight, angled at $22^{\circ}$, and angled at $45^{\circ}$. They can be changed remotely from the line controller. The robot is also equipped with a high-voltage touch-sensing unit, a nozzle cleaner and a wire cutter. A wire reel is mounted on the lateral table of the moving unit.

\section{Conclusion}

A welding robot system for large box structures has been developed and put to practical use to automate welding and to reduce labor requirements. The system automatically generates the robot operation data based on the design information from a three-dimensional CAD unit without the need for teaching by humans. This system was delivered to a client in September, 1999, since which time the system has been operating smoothly, allowing the factory to automate more than $80 \%$ of its welding work.

In order to save the effort of preparation of welding information on a three-dimensional CAD unit, the authors have already implemented KCONG on Solidworks, a mechanical three-dimensional CAD. This new version has a function of definition of welding paths with which operators can prepare welding information in a simple operation. The authors are now developing redundancy control function which automatically configures the position and orientation of a robot base and a positioning unit, so as to move in a favorable posture.

\section{References}

Kobayashi, M.; Ogawa, S. \& Koike, M. (2001). Off-Line Teaching System of a Robot Cell for Steel Pipe Processing, Advanced Robotics, Vol.15, No.3, (2001) (327-331).

Nagao, Y. \& Onoue, K. (2000). Teaching Method and Open Architecture Controller for Industrial Robots, Journal of the Robotics Society of Japan, Vol.18, No.4, (May 2000) (24-28), ISSN0289-1824.

Nagao, Y.; Urabe, H.; Honda, F. \& Kawabata, J. (2000a). Benifits of the Autoamted Robot Off-line Teaching System: KCONG, The Structural Technology, Vol.13, No.145, (June 2000) (44-48), ISSN0916-0426.

Nagao, Y.; Urabe, H.; Honda, F. \& Kawabata, J. (2000b). Development of a Panel Welding Robot System for Subassembly in Shipbuilding Utilizing a Two-Dimensional CAD System, Advanced Robotics, Vol.14, No.5, (2000) (333-336).

Nagao, Y. ; Urabe, H. ; Honda, F. \& Kawabata, J. (2001). Development of a Teaching-free Robot System for Welding Large Box Structures, Proceedings of the 32nd International Symposium on Robotics, pp. 971-976, Seoul, April 2001. 


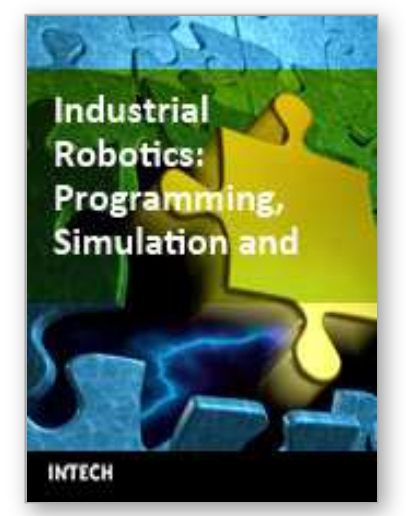

\author{
Industrial Robotics: Programming, Simulation and Applications \\ Edited by Low Kin Huat
}

ISBN 3-86611-286-6

Hard cover, 702 pages

Publisher Pro Literatur Verlag, Germany / ARS, Austria

Published online 01, December, 2006

Published in print edition December, 2006

This book covers a wide range of topics relating to advanced industrial robotics, sensors and automation technologies. Although being highly technical and complex in nature, the papers presented in this book represent some of the latest cutting edge technologies and advancements in industrial robotics technology. This book covers topics such as networking, properties of manipulators, forward and inverse robot arm kinematics, motion path-planning, machine vision and many other practical topics too numerous to list here. The authors and editor of this book wish to inspire people, especially young ones, to get involved with robotic and mechatronic engineering technology and to develop new and exciting practical applications, perhaps using the ideas and concepts presented herein.

\title{
How to reference
}

In order to correctly reference this scholarly work, feel free to copy and paste the following:

Yoichi Nagao, Hideaki Ohta and Fumihiro Honda (2006). A Teaching-Free Robot System Utilizing ThreeDimensional CAD Product Data, Industrial Robotics: Programming, Simulation and Applications, Low Kin Huat (Ed.), ISBN: 3-86611-286-6, InTech, Available from:

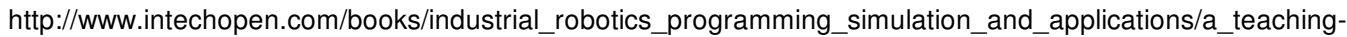
free_robot_system_utilizing_three-dimensional_cad_product_data

\section{INTECH}

open science | open minds

\author{
InTech Europe \\ University Campus STeP Ri \\ Slavka Krautzeka 83/A \\ 51000 Rijeka, Croatia \\ Phone: +385 (51) 770447 \\ Fax: +385 (51) 686166 \\ www.intechopen.com
}

\author{
InTech China \\ Unit 405, Office Block, Hotel Equatorial Shanghai \\ No.65, Yan An Road (West), Shanghai, 200040, China \\ 中国上海市延安西路65号上海国际贵都大饭店办公楼 405 单元 \\ Phone: +86-21-62489820 \\ Fax: +86-21-62489821
}


(C) 2006 The Author(s). Licensee IntechOpen. This chapter is distributed under the terms of the Creative Commons Attribution-NonCommercialShareAlike-3.0 License, which permits use, distribution and reproduction for non-commercial purposes, provided the original is properly cited and derivative works building on this content are distributed under the same license. 